\title{
Session extraordinary of the Medico-Psychological Society of Paris, held August, 1867, under the presidency of M. Paul Janet, Member of the Institute of France.
}

THe first meeting was held on August 10th, 1867. The President delivered an able address, of which the following is an abstract.

The reception within its bosom of so many eminent physicians, the distinguished representatives of mental medicine in the several countries of Europe, is an event that affords the highest pleasure to the Medico-Psychological Society, and is one also of which it may well feel proud. We hope this meeting may not be in vain, but that the social intercourse and business of this day may in future give rise to more intimate and more frequent association between our own and foreign learned societies, and between ourselves and those students and practitioners who here honour us with their presence. And further, may the progress of industry and science bring about the reunion of all peoples in one common brotherhood.

Yet it happens that notwithstanding the pacific character of industrial art, a certain degree of rivalry of interests will be felt among men. Not so, however, in the case of science, which knows no ocher rivalry than that generous emulation in the arduous pursuit which makes the student unwilling to be outstripped in the search after truth. A noble jealousy, that without creating lieart-burning and bate, ever provokes its subjects to further progress. . . Truth is too wide and too profound to be made the subject of exclusive theories. No formula can be invented to embrace it in its totality. Hence these large concours open to free investigation on all scieutific subjects throughout the world, where all may resort and bring with them their opinions, their reflections and their conclusions. Hence also those periodical reunions characteristic of the various learned societies, and likewise those rarer gatherings on a grander and international scale, known as congresses. So ambitious a title as this last it is not our wish to apply to the family reunion here present; but by whatever name it be designated it welcomes with pleasure all those who honour it with their presence, and we bid them accept in the same cordial manner we would render it, our modest hospitality.*

M. Lunier (inspector-general of asylums) rose to make a proposition relative to the statistics of the insane. He remarked how great confusion and error in medicine, and in administration, result from the absence of a uniform system of statistics in all places. An immense advantage would accrue from the preparation of such a system, which might be generally adopted. We are constantly in the habit of referring to statistical papers for assistance in the study of questions resting upon such facts, and it is a matter of the deepest regret that no international uniform system of statistics for Europe at large is in existence. This regret is felt as much by physicians in other countries as by our own countrymen. I therefore propose the nomination forthwith of a commission to proceed at once to the preparation of a scheme of statistics.

This proposition was accepted, and a commision formed of the following gentlemen :

Messrs. Roller and Griesinger for Germany; Bucknill and H. Tuke for England; Borrel for Switzerland; Pujudas for Spain; Lambroso for Italy ; and

* The foreign psychological physicians present were Drs. Griesinger, Roller, Harrington Tuke, Pujudas, Sibbald, Borrel, Cramer, Fistcherine, Berling, J. Masty Artigat, Mundy. 
Lunier, Jules Falret, and Brierre de Boismont for France. M. Motet to be general secretary to the commission.

M. le Baron Mundy next addressed the meeting on the subject of the public provision for the insane. He confined himself exclusively to the financial aspect of the question. He remarked that in France considerable sums were expended in the construction of new asylums which would be mnch more profitably employed in the inauguration of another system, that namely flourishing at Gheel, where so many " free labourers" were found collected together.

M. Lunier replied that the proportion of such labourers at Gheel is far from equalling that to be found in the best class of asylums of France.

MM. Brierre de Boismont, Moreau de Tours, Yujudas, and Mundy took part in the discussion of this question.

M. Lunier afterwards commenced the reading of an essay on the comparative legislation for lunatics in various couptries, and particularly on voluntary seclusion.

The meeting broke up at 6 o'clock p.m.

\section{Second Meeting, August 12th.}

Present : Messieurs Roller, Griesinger, Tuke, Pujudas, Kramer, Lambroso, Fistcherine, Sibbald, Cortyll, Jo. Masti y Artigas, together with a large number of corresponding members of the Society.

M. Gresinger opened the discussion by some observations on the question of instruction in mental medicine. In his opinion the separation of psychological medicine as a distinct subject from that of other maladies of the nerrous sys. tem, is uncalled for. He has obtained the sanction of his government to unile with the service of mental maladies one for nervous disorders, and thereby considers that an immense advantage is secured both to the pupils and the teacher, inasmuch as it is possible to observe the pliases of transition between nervous and mental derangement. In this "service" all the affections of the nervous centres are collected, and those mixed forms are encountered which are not referrible to insanity though they may constitute its groundwork. Nothing of the like kind exists in any other country, and in M. Griesinger's experience no prejudicial consequences to the insane have ever resulted from clinical instruction in asylums.

M. Lunier expressed his approval of such a clinical service, but stated that it would be impossible to institute the like in France; for the law intervened to prevent the removal of a patient suffering from a nervous malady to an asylum.

M. Moreau de Tours remarked that a scheme somewhat analogous existed at the Salpêtrière. The "service" of the hysteric, of the hystero-epileptic, and of the epileptic is separated from the "service" of the insane, but when epileptics are attacked with mania, and are dangerous, they are removed to the department for the insane. M. Griesinger's plan is excellent, but in France it would be encompassed by enormous difficulties.

$M$. Griesinger replied that the difficulties apprebended were not found at Berlin. The service worked without any embarrassment. Only a moderate number of patients is required for clinical instruction. I have one hundred patients, and find this number ample. The arrangement at the Salpêtrière is inadequate; something more is needed to adapt it to the scientific requirements of the age.

MF. Delasiauve.-The service alluded to is not constituted upon the plan proposed by $\mathrm{M}$. Griesinger. We bave not these examples of nervous disorders in general, but ouly cases of hysteria and epilepsy.

M. Laséque.-Since I have been called upon to give a course on insanity at the Faculty at Paris, I have adopted a nixed plan. I have received some cases of lunacy in my wards. I have been compelled to admit only quiet cases, and 
consequently the scheme is incomplete; but restricted as we are by laws and rules, it cannot be otherwise. The institution of a small asylum in the immediate contiguity of an hospital does not appear to us as likely to be attended by good results. The proposition of $\mathbf{M}$. Griesinger is a most interesting one; it is of undoubted advantage. both to teacher and taught, to have affections brought together which have so many points of contact, but we are unfortunately so placed that we cannot copy the institution recommended.

$M$. Griesinger in conclusion replied that he had not a discussion in view in reading his paper, his purpose being simply to state what he had done, und to discover that his plan was approved iu the interests of science.

M. Lambroso, of Pavia, communicated a series of meteorological observations, from which the conclusion seemed to follow that variations in atmospheric pressure exerted a marked influence on the number and violence of the convulsive seizures of epileptics and of the paroxysms of excitement of maniacal patients. The influence, moreover, of ozone and electricity, and of the wind, is much marked, and that of the moon even more so, for the greatest number of paroxysms and fits correspond with a new moon.

The scance terminated after an address by $M$. Morel, who proposed a vote of cordial welcome to the distinguished strangers who had honoured the invitation of the Society.

A banquet followed after the close of this séance, at which toasts were proposed by MM. Janet, Brierre de Boisinont, Griesinger, Morel, Lasèque, Harrington Tuke, Pujudar, Delasiauve, Cérise, Motet, and Linas.

The following séance took place on August 14th, under the presidency of $M$. Brierre de Boismont. The same foreign physicians, with the addition of Dr. Bucknill, and M. Bachel, of Venice.

$M$. Lunier completed the reading of his essay on comparative legislation.

He also announced that the labours of the commission appointed to prepare a general scheme of statisties, applicable to all countries, had so far advanced that it would be possible to forward a copy of proceedings to all the members, so that such observations as might at the time have escaped unheeded might be brought forward, and a general agreement on all points be thus attained. The tables forwarded will, after their revision, be returned to Paris and definitely adopted.

$M$. Borrel presentcd plans of a pavilion suited for four patients aud the residence of an assistant physician, as carried out at the asylum of Trefargier, in the Canton of Neufchatel, Switzerland.

$M$. Berstrier read a paper on the basis of a new general scheme of statistics, to which M. Lunier replied.

$M$. Brierre de Boisnont next addressed the meeting to the following effect : It was my purpose to address you on our intervention in judicial matters, but I do not desire to inflict upon you a collection of all the facts I have had under my notice during a career of considerable length. All, however, that I can now say is, that wo are called upon to render important services both to families and to magistrates; the knowledge acquired by us respecting mental disorder makes us competent to give our advice and opinion in this delicate question.

At the termination of the day's proceedings $D r$. Tuke asked permission to address a few words to the Society:

Mr. President and Gentlemen,-I can but imperfectly speak your language, but I canuot refrain, before we separate, making an attempt to express my feelings of gratitude to you, Mr. President and gentlemen, whom I have the honour of regarding as my confrères and fellow-workers. I thank you sincerely for the hospitality you have shown to us foreign visitors in so cordial a manner. On my part I sliould be happy to give you as hearty a reception in London as that which we have here received from you. 